\begin{tabular}{l||l} 
& $\begin{array}{l}\text { Gastern } \\
\text { Curopean } \\
\text { Countryside }\end{array}$ \\
\hline DOI: $10.1515 /$ eec-2017-0005 & $23^{\prime} 2017$
\end{tabular}

\author{
Emilia Sarno
}

\title{
Cross-border Inter-Adriatic Cooperation: A Case Study
}

\begin{abstract}
The paper highlights the cultural and legislative framework which favours the cross-border cooperation between the countries on the shores of the Adriatic Sea. It looks at the importance of geographical and socio-economic proximity and analyses the formation of the Adriatic-Ionian Euro-region. This context is useful for the development of those territories, considered marginal, which can renew their economies through cooperation. As a case study, what is analysed is the possible cross-border relations between the Italian region Molise and Montenegro. The two territories have several elements in common and can use cooperation as a means of renewing their economy. Furthermore, the crossborder cooperation is the right strategy to modernise the agricultural sector and strengthen the tourism. For this reason, the paper aims to highlight how the cooperation is the lens through which we can identify the territorial potential which, when amplified through comparison, will emerge more clearly.
\end{abstract}

Keywords: cross-border cooperation, European Union, Italian regions, Montenegro, 


\section{A historical and geographical context}

The Mediterranean ${ }^{1}$ is the physical space from which numerous civilisations arose and developed: including the Greeks and the Romans, as well as other peoples.

The Mediterranean is unitary and fragmentary, presented as both a space for communication and an area where relations between people of differing cultures could thrive; in fact, it is divided into a substantial number of seas forming basins and sub-basins (Trinchese and Caccamo 2008). The Adriatic Sea reflects the same typical characteristics of the Mediterranean and, for this reason, it represents an effectively natural connection rather than a division between Italy and the Balkans.

The structure of the Adriatic coast has, in fact, facilitated the settling of people from different neighbouring countries such as Italy, Slovenia, Croatia, Bosnia and Herzegovina, Montenegro and Albania, while their geographical location has contributed to exchanges and interactions (Baggio and Skoda Pashkja 2012). This proximity is singular insofar as the position of the Italian peninsula is easily accessible to the people and countries found on the eastern coast. For this reason, Italy has become an indispensable interlocutor.

Moreover, the proximity of the coasts finds continuity onto the main roads built by the Romans permitting for easy access to inland areas. For example, following the Egnatia road, which is a continuation of the Appia road, it is possible to reach the Bosphorus by crossing directly through present day Albania.

Trade relations are therefore of ancient descent. During the fifteenth and sixteenth centuries, the southern regions of Slavia (from today's Slovenia to Dalmatia and Montenegro) and internal territories of Herzegovina, Bosnia and Serbia exported fabrics, leather, fur, iron, lead, copper, mercury, timber, clay for dyes and building materials. In contrast, Italy provided fabrics from Florence and Ascoli Piceno, along with handicrafts, painted terracotta vases, drugs, valuable artefacts, soap, cotton, rice, oil, wine and citrus fruits (Scotti 2007).

1 On an issue of such importance the main references are: Braudel 1985; Harris 2005; Albera, Blok and Bromberger 2007; Fuschi 2008; Salvatori 2008; Baggio and Skoda Pashkja 2012. 
Several documents attest the various forms of alliance, or isopolitia, established between cities who had been from opposing sides since the Middle Ages (Carile 1995). The same urban planning ${ }^{2}$ systems were built on headlands along the Adriatic coast and forming strong commercial bonds because the cities were open to exchanges as well as confrontations and clashes (Fuschi 2008). Small and large ports punctuate areas of this stretch of sea, from the Upper Adriatic to the islands surrounding the Greek peninsula and include Trieste, Venice, Fiume, Ragusa (Dubrovnik), Split, Vlora, Durres, Zara, Corfù, Ancona, Termoli, Bari, Brindisi, Ithaca and Crete. However, the two most important cities were Dubrovnik and Venice. The first ${ }^{3}$ played a fundamental role because, along with Ancona, it represented one of the possible routes for the trafficking of commercial trade, linking both Western Europe and Italy to the East (Harris 2006). In turn, the Adriatic Sea has been dominated by Venice for centuries.

Between the two sides there was also cultural proximity, although it was not equal because Italian traditions were considered superior. It is then no wonder that there were consistently large migration flows from the east to the west coast (Botta et al., 2007). The Slavic presence in the territories of centralnorth Italy dates back to the beginning of the thirteenth century; however, migrations begin after the defeat of Kosovo in 1389. Of extreme importance is the date of the Turkish conquest of Constantinople in 1453 which paved the way for the Ottoman's expansion along the Balkans. From that moment Turkish pressure created the perfect conditions for the Slavs and Albanians to escape. The latter then began to be present in central and southern Italy, particularly in Marche, Abruzzo, Molise and Calabria.

However, the phenomenon is not unidirectional being that there are also Italian communities to be found on the East Coast with the most important being located in Kotor (now the town of Montenegro), where Venice rule enabled Italian settlements to come from Venetian areas.

These elements highlight such a strong contiguity between the territories touched by the Adriatic Sea that not even the conflicts between the Ottoman Empire and Christian Europe were able to stop it. Only Italian irredentism

2 See the volume edited by Pavia 1990, which collects technical studies on the plants of urban city on the two shores of the Adriatic.

3 The ancient city of Ragusa is now known as Dubrovnik; the two place names attest to the dual soul of this city: the Greek-Roman and Slavic. 
and German nationalism, with their expansionist ambitions, created a rift in the Balkans which continued from the beginning of the twentieth century to 1975 when the Treaty of Osimo established the borders between Italy and exYugoslavia. The Treaty of Osimo marked the end of the "long Adriatic postwar era and opened up the possibility of an economic cooperation to trigger positive inter-relations between the two countries and the more delicate relations between locals and ethnic minority groups" (Iuso 2002:163).

\section{The different formulas for cross-border cooperation and the establishment of the Adriatic-Ionian Euro-region}

The geographic and cultural proximity has made the consolidation of multilateral relations between the Adriatic countries possible and has tried to sustain both local processes of growth and cooperation among people. As mentioned in the previous paragraph, trade arrangements started to be underwritten in the 1970s. The economic cooperation between the Member States of the European Economic Community and the Mediterranean countries was legitimised at the Paris Conference in 1972 (Cafaro 2012). The path has been neither easy nor linear because of the long and painful disintegration of ex-Yugoslavia along with the domestic political events of Greece ${ }^{4}$. However, a mature conception of cooperation, which led to partnerships, has gradually developed (Scorrano 2006).

This development was made possible by the European Union which, since 1992, has been pursuing both a vertical integration between European and international institutions and a horizontal integration through an arrangement of a free trade area (Vellano 2014). In particular, the European Commission launched an initiative in 1990 known as INTERREG for the promotion of cross-border networks both in European countries and the countries of Central and Eastern Europe ${ }^{5}$. In this context, there was much interest in the international organisation named the Adriatic-Ionian Initiative, promoted

4 Between 1967 and 1974, Greece was ruled by the military.

5 The 1990 event was the first of a long series of INTERREG which favored cultural, economic and social issues. 
at the Conference in Ancona ${ }^{6}$ on 19th and 20th May 2000. It represented "an instrument aimed at strengthening and consolidating the cooperation between the countries on the two sides of the sea in a wide range of areas such as culture, inter-university cooperation, the fight against organized crime, environmental protection, the boosting of tourism, economic cooperation, the development of transport and maritime cooperation" (Rossi 2003: 1).

This initiative also had another advantage. In fact, it was the starting point for the creation of important organisations such as the Adriatic and Ionian Euro-region. They are the result of a precise political orientation: to set up European groups of cross-border cooperation (EGCC). This strategy regulates relations between two or more EU Member States, while also the non-EU countries and allows the organisations of several States to be associated without subscribing to an international agreement, ratified by national parliaments (Abbati 2010).

The Adriatic Euro-region was founded by 22 territorial entities, which are Italy, Slovenia, Croatia, Bosnia and Herzegovina, Montenegro and Albania, and in Poland in 2006. These were not only European member states, but also both pre-accession countries and states not interested in entering the UE joined the Adriatic Euro-region. The general aims here were the strengthening of stability of both the Adriatic and especially the Balkan regions. The specific objectives were the promotion of a sustainable development and an economic and social cohesion among the participating institutions (Marušić 2008).

This institution has led to the creation of a group of cross-border cooperations (EGCC) and has generated a careful consideration of the, "Adriatic Sea which from the border line becomes a unifying element of peoples and nations. Countries that had previously had serious problems with each other

6 The Conference was attended by the Heads of Government and Foreign Ministers of the six riparian countries (Albania, Bosnia and Herzegovina, Croatia, Greece, Italy and Slovenia, to which is added the Yugoslav Federation after the democratic breakthrough in November 2000).

7 The initial members are: the Italian regions of Abruzzo, Friuli Venezia Giulia, Emilia Romagna, Marche, Molise, Puglia and Veneto, the Slovenian municipality of Isola, Erzegovese canton of Narenta (Croatia), the municipality of Kotor (Montenegro) six Albanian prefectures: Fier, Shkoder, Durres, Alessio, Tirana and Vlora. See the statutes of the foundation of the Adriatic Euro-region, 2006 on the website: www. adriaticeuroregion. org. 
then became partners in a partnership focused on the Adriatic Sea as the main "resource common to all countries" (Leoni 2007:64-65). From this perspective, the next step is understandable; namely, the extension of this Euro region in the Adriatic-Ionian Sea.

In Termoli on $15^{\text {th }}$ January 2013, the general assembly of the Adriatic Euro-region approved the statutes amendment to extend into the Ionian basin, giving it the name of the Adriatic-Ionian Euro-region ${ }^{8}$ and admitting new members, such as three Greek regions. It was conceived as an innovative structure of interregional and transnational cooperation that aimed to strengthen both democratic processes and the European integration of the Balkan countries. It can be considered the first "EU macro-regional strategy" to involve many countries (Albania, Bosnia and Herzegovina, Montenegro and Serbia) cooperating with the European Member States (Croatia, Greece, Italy and Slovenia). Its creation aims to both consolidate economic cooperation and develop a common governance of shared problems such as environment, energy, transport, fishing and coastal management, rural development, tourism, cultural and university cooperation, citizen protection and cooperation ${ }^{9}$.

The main strategy is focused on the opportunities of the Blue Economy (aquaculture, fishing, blue biotechnology, marine and maritime services, etc...) and a sustainable development of coastal tourism. However, research, innovation and the strengthening of small and medium-sized enterprises are due to be enhanced. In fact, its aims are to exceed the vision of a Europe that pays little attention to the Mediterranean and the Balkans, thanks in addition to the key role of Italy and mainly of the Italian regions ${ }^{10}$ which take advantage of the European contributions encouraging bilateral and multilateral combined projects.

8 See the statute of the Adriatic-Ionian Euro-region Foundation, 2013. This is the third of the continents, after the Baltic Sea and the Danube. The documentation is available on the official website: www.adriaticionianeuroregion.eu.

9 See the statute of the Euro-region Adriatic-Ionian Initiative, 2013, available on the official website: www.adriaticionianeuroregion.eu.

10 For an examination of the results of cooperation experiences see Herlja 2009; Ricciardelli and Urso 2013; Custro 2013. 
In this context, a research project ${ }^{11}$ has been set up to establish stable cross-border relations between the Italian region of Molise and Montenegro. The two territories have several elements in common and, as the next paragraph clarifies, they can use the cooperation as a means of renewing their economy. Moreover, as will be shown, the cross-border cooperation is the right strategy to modernise the agricultural sector and strengthen tourism.

\section{Common factors between Italian region Molise and Montenegro}

The favourable socio-political environment has allowed for different approaches to be employed between the territories of the two shores of the Adriatic Sea, leveraging ancient and more recent proximities.

But what are the common factors between Molise and Montenegro?

First, they have homogeneous environmental features such as coasts and mountains. These are two factors that have expressed common anthropological models. The mountainous and hilly areas were places for shepherds and farmers, where agriculture has been replaced by transhumance (Sarno 2013). This anthropological-territorial model has persisted through the centuries and has only been interrupted by the discontinuity of the industrial society, requiring mountain and rural areas to find a new centrality (figs. 1-2).

The coast has given way to an ambivalent pattern. It has become the crossroads for meetings and exchanges and of dangers coming from the sea. It contains fundamental economic potential, such as the traditional fishing industry and commercial trade, which are as current as tourism. In relation to these two landmarks, Molise and Montenegro have plenty of areas of high naturalness and biodiversity: "Montenegro can be divided into two main bio-geographical regions - Mediterranean and Alpine - and has a very wide range of ecosystems and habitat types for a country of its size. There is an area of flora and fauna from the cold mountainous north and south, to the warm Mediterranean coast in the west" (Nikolić and Krivokapić 2015:27).

11 This study is part of a research project started in 2011 by ARSIAM Molise (Regional Agency of Agricultural Research of the Italian region of Molise) as part of a cross-border programme of cooperation between Molise and Montenegro of which the author is coordinator. 
On the other hand, Molise has a composite system, diversified and full of ecological niches which increase the degree of biological diversity to the highest levels in Europe (Di Blasi et al., 2001). This is confirmed by floristic research which indicates that there are more than 2,500 species of regional flora.

Biodiversity, as the third common landmark, is a resource which can be used for the economic wealth of the areas in terms of strong rural vocation. Thanks to it, the agriculture has proven to be one of the economic pillars of these areas and now requires a precise reflection to develop a new rural vision. With this in mind, tourism can also expand its strategic value becoming a starting point for territorial promotion.

What is more, environmental factors and the lack of consideration given to the innovation of economic processes have caused territorial imbalances both in Montenegro and Molise. Populations are concentrated in the major towns or on the coast, whereas the mountainous and hilly areas are subject to depopulation.

In fact, Molise and Montenegro are not up-to-date regarding social, economic and organisational matters, due to another common geographic factor: peripheral location. The lack of accessibility caused by the orographic structure of the territories has influenced the development of infrastructures and has limited territorial relations which, nowadays, are essential. It is this fundamental to join European organisations and projects and to participate in inter-Adriatic relations to solve this problem and aim at developing their potential.

Figures 1-2. Maps of Molise, a region of central Italy and Montenegro
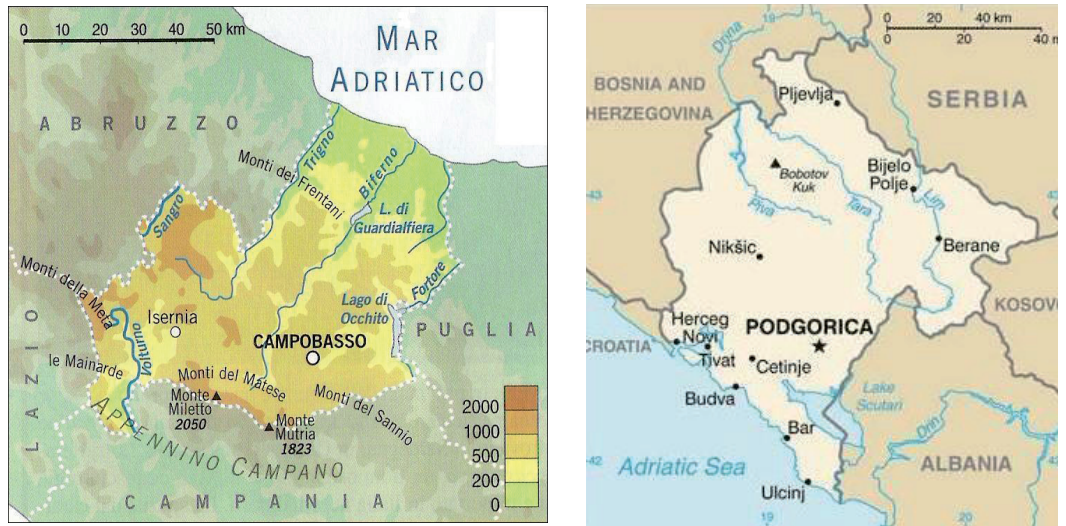


\section{Cooperation for a new rural vision}

Both transhumance and agriculture, which are focused on local consumption, were two important pillars of the Molise and Montenegro economies with organisational methods being developed in the diffused presence of those family-run farms having difficulty in selling their products. One of the objectives currently pursued is the development of chains to improve the agro-food sector such as the processing of meats, dairy products or the wine production. The integration between agriculture, livestock, industry and food trade through both the unification of small units and the modernisation of production facilities is then to be encouraged.

However, local products, such as some dairy produce, honey, floral resources and regional species of grapevine, which are considered as niche but represent the specialities of these territories, must not be neglected. For this reason, a new rural vision can be beneficial to the territorial and demographic imbalances, caused by the flight from small areas to cities, in search not only of professional opportunities but also an urban quality of life. Moreover, both territories have areas at different altitudes which are not suitable for farming but are functional for other forms of rural development, thanks to their environmental and landscape qualities.

In the perspective of sustainability, the projects and cooperation experiences must necessarily consider the reflection on rural areas as crucial places of development (Van der Ploeg 2006; Woods 2005). Sustainability should be considered as the interaction of four essential elements: nature, culture, economic factors and social ties: "The diversity, which can be perceived in terms of biodiversity of landscape and historical heritage, but also as an opposition to the approval to the ways of life and consumption, becomes a fundamental element for rural recovery. The new concept of rural is part of a broad discussion about local development, based by the exploitation of local resources and local specifics which focuses on the conservation of the complexity of environmental, economic, social, and the balance between places" (Ruby 2007: 8).

For this reason, providing multi-functional rural activities is the best strategy: organic crops, horticulture, educational and hypnotherapy farms, farm holidays, and nature trails to be used also for non-competitive sports (Van Huylenbroeck et al. 2007). Moreover, multi-functionality becomes an instrument for territorial promotion (Fuschi 2012) because, if it is supported 
by an adequate reorganization of small centres through the development of services and infrastructures, constitutes a reduction in migrations and can create job opportunities.

In this context, cooperation becomes fundamental, especially if it is decentralised, because "it has a concrete and measurable dimension which is made of interaction, reciprocity, dialogue and collaboration" (Pollice 2013:10). It must be based on two factors - research and innovation - which leads to the emergence of planning that can both identify resources and opportunities and, above all, to define coalitions and lasting decision-making structures capable of responding to changes relating to economic situations (Rinaldi 2013:159).

Establishing stable relationships between research institutes, universities and firms, the paths of applied research can be implemented to promote the typical traits of Molise and Montenegro, to select technological and biotechnological instruments, which are useful for improving production, and to identify new forms of marketing. The exchange of know-how may both support the productions of each area reciprocally and lead to the implementation of common products.

Other project activities are necessary to strengthen the protection of valuable landscapes through the identification of both forms of accessibility and of conditions of exploitation, whereas feasibility studies are functional for the establishment of eco-museums ${ }^{12}$. The cooperation can be an advantage both scientifically and operationally, while any action, instead of remaining isolated, takes advantage of the establishment of an inter-institutional and cross-border network.

The common production of primary products also deserves attention, whose quality by type must be improved especially from the point of view of environmental safety. In these cases, the training of both specific figures and entrepreneurs becomes crucial to adopt environmentally-friendly defensive strategies with a low environmental impact. If ecological purposes are turned into concrete commitments, then quality will become a primary factor.

These choices are in line with EU directions and cross-border cooperation. In this sense, they could be the right synergy for the expansion;

12 The establishment of eco-museums would move in line with a cross-border project already made ADRIAMUSE, which has enhanced the museums on the two shores of the Adriatic; see its website: http://www.adriamuse.org/. 
for example, regarding organic farming. Recently the European Commission has reaffirmed its importance and aims to promote its diffusion by facilitating transition to organic farming, by introducing the possibility of joining a system of group certification and by facilitating exports ${ }^{13}$. In this sense, training programmes, internships and work experiences can develop programmatic actions which, if created 'in tandem', can develop a system of local and partial experimentations.

In short, cooperation is not only a tool for disseminating a new rural vision but the lens through which to identify the territorial potential which, amplified by comparison, will emerge more clearly. However, aside from requiring both the foresight of authorities and enterprises and the efforts of experts and researchers, the cohesion of local communities and their active participation in decision-making and building synergies with other economic activities such as tourism.

\section{From tourism to tourisms: a shared perspective}

In 2014, according to information from the World Tourism Organization (UNWTO), Mediterranean countries are still a strong attraction for tourists despite the current economic crisis and the need for new sector management policies. For these reasons, many European cooperation organisations have identified tourism as a key objective for overcoming the disparity between places with high attractiveness and areas marginally touched by large flows of tourists.

Tourism is definitely an asset to Molise and Montenegro, although the development of the first in this sector is incomparable to that of the latter both in economic terms and for the number of predominantly foreign visitors. However, the document stipulated by the Ministry of Tourism and Environment of Montenegro in 2008 - Montenegro Tourism Development Strategy to 2020 - shows the challenges of contemporary tourism in line with the latest literature (Conrady and Buck 2011), indicating the competition inherent to a global market and increasingly demanding tourists. The tourist boom experienced by this young country does not camouflage the critical

13 See the website: http://europa.formez.it/content/agricoltura-organic-newproposed-commission-european. 
issues investing Molise where the sector is not completely taking off. For these reasons, the afore-mentioned Montenegrin document focuses on some important objectives similar to the tourist planning of Molise in 2013; namely, the diversification of supplies, out of season experiences, improvement of tourist accommodation and infrastructures.

Therefore, it is necessary to overcome the development model based on seaside and seasonal tourism both to enhance different territorial potentialities and to estimate the plurality and heterogeneity of tourist demand. Though with the due distinctions, the shared prospective is represented by the shifting from tourism to tourisms, from the stereotypical figure of tourist to that of sensitive and aware travellers (Corna Pellegrini 2007; Page 2011).

Promoting territorial potential means focusing on rural tourism as an integral part of the new rural dimension, as previously discussed. Moreover, local specialties, from wine to cheese, can be exploited in this context for connoisseurs of taste. Moreover, natural areas, which are present in both countries, provide the suitable habitat for doing sports such as hiking and mountain biking and are generally aimed at nature lovers.

However, this is not enough. It is essential to create both intra-territorial and inter-territorial synergies between the different opportunities. Otherwise, every formula - rural, gastronomical, oenological, naturalistic or cultural may appear weak: "In this way, single resources, which would not be able to generate an autonomous tourist demand, acquire an added value when they are incorporated into a system. In the same way, internal or rural areas can get out of their marginal position and find a place in the local tourist system" (Rinaldi 2013:156). From this perspective, the integrated resources management and the activation of bottoms-up policies (Dallari 2007) both give centrality to local communities and respect the guidelines of the European Charter of Sustainable Tourism (Dematteis et al. 2010).

A farsighted planning of tourist accommodation rather than a focus on big hotel facilities should promote new models of hospitality such as a 'decentralised hotel. The use of existing structures has the advantage of putting the tourist in the social network of the host community reducing environmental impact. Therefore, cooperation, in this case, is the pick for a common and shared reflection on the challenges of global tourism. Programmed actions must aim to train experts who know how to enhance local resources and build those synergies previously mentioned, but also know how to support the qualitative development of tourist accommodation. 
The involvement of local populations in permanent laboratories for meetings and seminars appears useful to turn them into host communities able to share their territory and not to distract tourists eager to escape from their routine, but to place the focus on travellers interested in learning and understanding.

Finally, thematic "cross-border" routes can be designed and created. A significant attention to maritime transport, but mainly to tourist ports-a priority objective in the documents of the Euro-region. It becomes the basic factor to create pathways to make Molise and Montenegro known 'in tandem.' Thus, the cooperation acquires an added value because it can satisfy the needs of travellers attentive to cultural values and fascinated by the comparison.

\section{References}

Adriatic Euroregion 2006 Statuto. Available: www. adriaticeuroregion.org.

Adriatic-Ionian Euro-region 2013 Statuto. Available: www.adriaticionianeuroregion. eu

Albera, D., Blok, A. \& Bromberger, C. 2007 Antropologia del Mediterraneo, Milano: Guerini editore.

Abbati, G. 2010 Gruppo Europeo Cooperazione Territoriale ...macroregioni e Mediterraneo, EU Committee of the Regions.

Baggio, F. \& Skoda Pashkja, A. 2012 Mediterraneo crocevia di popoli, Città del Vaticano: Urbanian University Press.

Bignante, E. \&Scarpocchi, C. 2011'Cooperazione internazionale e azione territoriale: la sfida della cooperazione decentrata' in A. Di Blasi (ed.) Il futuro della geografia: ambiente, culture, economia. Proceedings of the XXX Italian Geographic Conference, pp. 55-58. Bologna: Patron.

Blasi, C. et al. 2001 'La biodiversità nella problematica ambientale' in Note sullo stato dell'ambiente della provincia di Campobasso, Campobasso.

Botta, F., Garzia, I. \& Guaragnella, P. (eds) 2007 La questione adriatica el'allargamento dell'Unione Europea, Milano: Franco Angeli.

Braudel, F. 1985 La Méditerranée, l'espace et l'histoire, Parigi: Flammarion.

Cafaro, S. 2013 'L'Unione per il mediterraneo: storia di una stratificazione normativa' in A. Ricciardelli \& G. Urso (eds) La Puglia nel Mediterraneo Nuove prospettive per la cooperazione Euro-mediterranea, Università del Salento, pp. 21-42.

Carile, A. 1995 'La marineria bizantina in Adriatico nei secoli VI-XII' in Adriatico mare di molte genti incontro di civiltà, pp. 1-47.

Conrady, R. \& Buck M. (eds) 2011Trends and Issues in Global Tourism 2011, Berlin Heidelberg New York: Springer. 
Corna Pellegrini, G. 2007 Geografia diversa e preziosa, Roma: Carocci.

Dallari, F. 2007 'Distretti turistici tra sviluppo locale e cooperazione interregionale' in F. Bencardino \& M. Prezioso (eds) Geografia del turismo, Milano: McGraw-Hill, pp.195 - 215 .

Dematteis, G., Lanza, C., Nano, F. \& Vanolo, A. 2010 Geografia dell'economia mondiale, Torino: UTET.

Fuschi, M. 2008 'La città mediterranea. Tra stereotipi e frammentazioni di scala' in M. Fuschi (ed.) Il Mediterraneo Geografia della complessità, Milano: FrancoAngeli, pp. 53-100.

Fuschi, M. 2012 'La valorizzazione turistica dei paesaggi agro-culturali: una interpretazione geografica' in Annali del Turismo (1): 23-38.

Harris, R. 2006 Dubrovnik A Histor, London: Saqi.

Harris, W. 2005 Rethinking the Mediterranean, Oxford.

Iuso, P. 2002 'Percorsi italiani nei Balcani del Novecento' in Meridiana (45): 161-178.

Leoni, S. 2007 'La partecipazione della Regione Emilia-Romagna all'Euroregione Adriatica' in Le istituzioni del federalismo, Bologna, pp. 62-71.

Marušić, H. 2008 Cooperazione transfrontaliera Adriatica dall'INTERREG verso una euroregione Adriatica. Extract from the Master thesis at the Institute of European Studies "Alcide de Gasperi". Roma.

Monastiriotis, V. \& Petrakos, G. 2009 Local Sustainable Development and Spatial Cohesion in the Post-transition Balkans: in search of a developmental model, Hellenic Observatory Papers on Greece and Southeast Europe.

Montenegro Ministry of Tourism and Environment (ed.) Montenegro Tourism Development Strategy to 2020, December 2008.

Nikolić, G. \& Krivokapić, M. 2015 'Montenegro: Land and People- Nature and Demography' in E. Sarno (ed.) Molise-Montenegro Cross-border Cooperation, Roma: Aracne, pp. 27-41.

Page, S. 2011 Tourism Management: An Introduction, Oxford: Elsevier, 4th edn.

Pavia, R. (ed.) 1990 Città e territori del mondo Adriatico, colloquio internazionale di studio Italia-Jogoslavia, Franco Angeli, Milano.

Pollice, F. 2013 'La Puglia nel Mediterraneo. Il valore strategico della cooperazione' in A. Ricciardelli, A. \& G. Urso (eds) La Puglia nel Mediterraneo Nuove prospettive per la cooperazione Euro-mediterranea, Università del Salento, pp. 5-19.

REGION MOLISE 2013 Programma di promozione del turismo anno 2013. Available: www.quiregionemolise.it.

Ricciardelli, A. \& Urso, G. (eds) 2013 La Puglia nel Mediterraneo Nuove prospettive per la cooperazione Euro-mediterranea, Università del Salento.

Rinaldi, C. 2013' La cooperazione in ambito turistico-rurale: un caso-studio tra le isole del Mediterraneo' in A. Ricciardelli \& G. Urso (eds) La Puglia nel Mediterraneo Nuove prospettive per la cooperazione Euro-mediterranea, Università del Salento, pp. 151-170. 
Salvatori, F. (ed.) 2008 Il Mediterraneo delle città, Roma:Viella.

Rossi, A. 2003 Cooperazione adriatica: progetti, esperienze, prospettive. Ancona: Associazione Alessandro Bartola.

Sarno, E. 2013 'From the Historical Tyranny of the Balkans to Pluralism: a new historical-geographical reading, in Review of Historical Geography and Toponomastics VIII (17-18): 187-198.Scorrano, S. 2008 'L'Unione Europea e il Mediterraneo: dallassistenzialismo alla cooperazione' in M. Fuschi (ed.) Il Mediterraneo. Geografia della complessità, Milano: FrancoAngeli, pp. 206-240.

Scotti, G. 2007 Un mare, due sponde, Montefalcone.

Trinchese, S. \& Caccamo, F. 2008 Adriatico contemporaneo. Rotte e percezioni del mare comune tra Ottocento e Novecento, Milano: Franco Angeli.

Vellano, M. 2014 La cooperazione regionale nell'Unione Europea. Torino: Giappichelli.

Van Der Ploeg, J. 2006 Oltre la modernizzazione. Processi di sviluppo rurale in Europa,Catanzaro: Rubbettino.

Van Huylenbroeck, G., Vandermeulen V., Mettepenningen, E. \& Verspecht, A. 2007 'Multifunctionality of Agriculture: A Review of Definitions, Evidence and Instruments' in Living Reviews in Landscape Research 3.Woods, M. 2005 Rural Geography, Sage Publications. 